\title{
RENDIMENTO DO FEIJOEIRO EM SEMEADURA DIRETA CONSIDERANDO-SE A PROFUNDIDADE DE ADUBAÇÃO E LÂMINAS DE IRRIGAÇÃO
}

Élcio das Graça Lacerda ${ }^{1}$, Haroldo Carlos Fernandes², Mauri Martins Teixeira ${ }^{3}$, Daniel Mariano Leite ${ }^{4}$, Ismail

Ramalho Haddade ${ }^{5}$

\section{RESUMO}

O controle da irrigação e a localização do fertilizante no solo constituem critério preponderante para o êxito da produção de uma cultura. Objetivou-se, com o presente trabalho, avaliar a cultura do feijão em função da profundidade de deposição do adubo e das lâminas de irrigação em sistema de semeadura direta, em um Latossolo, textura argilosa. Utilizou-se a combinação de 5 lâminas de reposição de água da evapotranspiração (ETo) da cultura $(25,50,75,100$ e $125 \%$ e quatro profundidades de adubação $(0,05 ; 0,09 ; 0,12$; e $0,17 \mathrm{~m})$, no delineamento inteiramente casualizado (DIC) em parcelas subdivididas com três repetições. Utilizou-se um trator, marca New Holland, modelo TL 85 E, uma semeadora-adubadora marca BALDAN modelo PLB 3 e um pivô central da marca FOCKING. O estande utilizado foi de 240.000 plantas ha-1 da cultivar BRSMG Madrepérola. Não houve diferenças significativas da profundidade de adubação para as variáveis, número de vagens por planta e massa de 100 grãos. A profundidade de adubação influenciou o número de grãos por vagens e a produtividade da cultura. As lâminas da ETo influenciaram a massa de 100 grãos, número de vagens por planta, número de grãos por vagens e produtividade da cultura.

Palavras-chave: mecanização, evapotranspiração, produtividade, Phaseolus vulgaris.

\section{ABSTRACT}

\section{INFLUENCE OF THE DEPTH OF FERTILIZATION AND IRRIGATION ON THE BEAN CROP IN NO TILLAGE}

Irrigation control and the location of fertilizer in the soil are predominant criteria for successful crop production. The objective of this study was to evaluate how the bean crop depends on the depth of fertilizer deposition and irrigation depth in no tillage in a clayey-texture Latosol. We used a combination of five depths of water replacement for evapotranspiration (ETo) from the culture $(25,50,75,100$ and 125\%) and four depths of fertilization $(0.05,0.09$, 0.12 , and $0.17 \mathrm{~m}$ ) in a completely randomized design (CRD) with three replications. We used a tractor, New Holland brand, model TL 85 E, a planter brand BALDAN model PLB 3:01 and an irrigation pivot brand, FOCKING. The plot used consisted of 240,000 plants ha ${ }^{-1}$ of the cultivar BRSMG Marepérola. For depth of fertilizer there was no significant difference for the variables number of pods per plant and mass of 100 grains. The depth of fertilization influenced the number of grains per pod and yield. The depths of ETo influenced the weight of 100 grains, number of pods per plant, number of grains per pod and yield.

Keywords: mechanization, evapotranspiration, yield, Phaseolus vulgaris.

\section{Recebido para publicação em 17/09/2012. Aprovado em 19/11/2013.}

1 - Agrônomo, Prof. do Instituto Federal do Espírito Santo - Campus Santa Tereza, ES, email: elciodgl@hotmail.com

2 - Eng. Agrícola, Prof. Associado Departamento de Engenharia Agrícola, UFV - Campus Viçosa, MG.

3 - Eng. Agrônomo, Prof. Associado Departamento de Engenharia Agrícola, UFV - Campus Viçosa, MG.

4 - Lic. em Ciências Agrícolas, Doutorando em Engenharia Agrícola, UFV - Campus Viçosa, MG.

5 - Eng. Agrônomo, Prof. do Instituto Federal do Espírito Santo - Campus Santa Tereza, ES. 


\section{INTRODUÇÃO}

A cultura do feijão (Phaseolus vulgaris L.) é de expressiva importância econômica no cenário mundial, pois, além de ser um dos mais importantes componentes da dieta alimentar da população, é reconhecidamente uma excelente fonte proteica, possui bom conteúdo de carboidratos, vitaminas, minerais, fibras e compostos fenólicos com ação antioxidante que auxiliam na redução da incidência de doenças.

Algumas características apresentadas pelo feijoeiro, tais como: sistema radicular pouco profundo, além de ciclo reduzido (60 a 100 dias), exige que, durante a adubação, os nutrientes sejam aplicados próximo ao sistema radicular da planta, a fim de serem absorvidos por ela no momento necessário (ROSOLEM; MARUBAYASHI, 1994). O efeito benéfico da adubação profunda no solo sobre as culturas é relatado por Chaib et al. (1984), que verificaram melhor desenvolvimento radicular do feijoeiro quando se efetuou a adubação em maior profundidade, em relação à convencional.

A técnica de semeadura direta consiste na colocação da semente em um solo não convencionalmente preparado, causando mínima mobilização, possibilitando a permanência de restos vegetais das culturas anteriores na cobertura do solo (BRANQUINHO et al., 2004). Stone e Moreira (2000), comparando os efeitos de sistemas de preparo do solo na produtividade do feijão, observaram que os sistemas de preparos do solo afetou significativamente o número de vagens/planta e o de grãos/vagem. Kluthcouski e Stone (2003) constataram que a incorporação do fertilizante, a $0,15 \mathrm{~m}$ de profundidade, aumentou em $75 \%$ o rendimento do feijoeiro sem irrigação em relação à adubação convencional. Os autores sugerem pesquisas, no que se refere à profundidade do fertilizante em relação às sementes, para avaliar os possíveis efeitos na produtividade das culturas.

De acordo com Lopes et al. (2004), o conhecimento da quantidade de água requerida pelas culturas, constitui-se em aspecto importante na agricultura irrigada para que haja uma adequada programação do manejo de irrigação.

Com o presente trabalho, objetivou-se avaliar os efeitos da produtividade do feijoeiro em função da profundidade de deposição do adubo e lâminas de irrigação em sistema de semeadura direta.

\section{MATERIAL E MÉTODOS}

Este trabalho foi realizado no Instituto Federal de Educação, Ciência e Tecnologia do Espírito Santo (IFES), Campus de Santa Teresa, localizada no município de Santa Teresa, região Serrana do Espírito Santo, no período de 09 de agosto a 27 de outubro de 2011, sob um pivô central em um Latossolo Amarelo Eutrófico de textura argilosa.

O local do experimento apresenta uma altitude média de $150 \mathrm{~m}$ e fica situado entre as coordenadas $19^{\circ} 48^{\prime} 36^{\prime \prime}$ de latitude sul e $40^{\circ} 40^{\prime} 48^{\prime \prime}$ de longitude oeste de Greenwich.

No experimento, foi utilizado um trator marca New Holland, modelo TL 85, uma semeadoraadubadora de plantio direto marca BALDAN, modelo PLB 3 com sulcadores do tipo haste, com capacidade de até $0,20 \mathrm{~m}$ de profundidade, e um pivô central da marca FOCKING, modelo AF274015. Para fins de dessecação da vegetação existente antes do plantio, foi aplicado o herbicida sistêmico Glyphosate, na dosagem de 3,0 $\mathrm{L} \mathrm{ha}^{-1}$. Utilizouse um estande de 240.000 sementes de feijão da cultivar BRSMG Madrepérola e $42 \mathrm{~g}$ de adubo por metro linear da formulação.

Utilizou-se a combinação de quatro profundidades de adubação $(0,05 ; 0,09 ; 0,12$; e $0,17 \mathrm{~m}$ ) e cinco lâminas de reposição de água da evapotranspiração (ETo) $(25,50,75,100$ e $125 \%)$ da cultura do feijão em função dos teores de água do solo, conforme apresentado no Quadro 1.

$\mathrm{O}$ experimento foi montado de acordo com o delineamento inteiramente casualizado, em parcelas subdivididas, sendo que nas parcelas encontravam-se as lâminas de reposição de água da evapotranspiração e nas subparcelas as profundidades, com 3 repetições por tratamento, totalizando 60 unidades experimentais, de $60 \mathrm{~m}^{2}$ de área.

$\mathrm{O}$ rendimento da cultura foi determinado pela colheita, realizada manualmente, de $6 \mathrm{~m}^{2}$ de cada 
Quadro 1. Lâminas totais de água repostas via irrigação + precipitação na cultura do feijoeiro, em função das evapotranspiração

\begin{tabular}{lccccc}
\hline $\begin{array}{l}\text { ET0 } \\
\text { mm }\end{array}$ & $\begin{array}{c}25 \% \\
(\mathrm{~mm})\end{array}$ & $\begin{array}{c}50 \% \\
(\mathrm{~mm})\end{array}$ & $\begin{array}{c}75 \% \\
(\mathrm{~mm})\end{array}$ & $\begin{array}{c}100 \% \\
(\mathrm{~mm})\end{array}$ & $\begin{array}{c}125 \% \\
(\mathrm{~mm})\end{array}$ \\
\hline Lâmina & 81,03 & 162,06 & 243,09 & 324,13 & 405,16 \\
\hline Precipitação & 28,10 & 28,10 & 28,10 & 28,10 & 28,10 \\
\hline Total & 109,13 & 190,16 & 271,19 & 352,23 & 433,26 \\
\hline
\end{tabular}

sub parcela, no estádio fenológico do feijão de maturação e colheita.

Para análise estatística utilizou-se o software SAS 9.2, sendo os modelos escolhidos com base na significância dos coeficientes de regressão, utilizando-se o teste " $t$ "e adotando-se o nível de $5 \%$ de probabilidade, no coeficiente de determinação $\left(\mathrm{R}^{2}=\mathrm{SQ}\right.$ regressão/SQ tratamento $)$ e no fenômeno biológico.

\section{RESULTADOS E DISCUSSÃO}

Houve efeito significativo dos tratamentos quanto à profundidade de adubação somente para quantidades de grãos por vagens e produtividade da cultura. Aderivada da equação da regressão (Equação 1) demonstra que profundidade de adubação de 0,11 m e a reposição da ETo de 120,73 \% proporcionaram o maior número de grãos por vagens de 5,548 grãos, já a profundidade de $0,09 \mathrm{~m}$ de adubação e a lâmina de $125 \%$ da ETo proporcionaram a maior produtividade $\left(3045 \mathrm{~kg} \mathrm{ha}^{-1}\right)$.

Houve efeito significativo das lâminas de água dos tratamentos para todas variáveis de massa de 100 grãos, de número de vagens por planta, de número de grãos por vagens e de produtividade da cultura, sendo a melhor lâmina a de $125 \%$ da ETo, a qual representou uma quantidade total de 433,26 $\mathrm{mm}$ de água fornecida à cultura, durante todo $\mathrm{o}$ ciclo.

A massa estimada de 100 grãos aumentou com o aumento na reposição da lâmina de evapotranspiração, até ser atingido um ponto de máximo (112,27 \%, correspondente a 395,44 mm de água), conforme apresentado na Figura 1, na qual se apresenta a curva obtida utilizando-se a Equação 1.

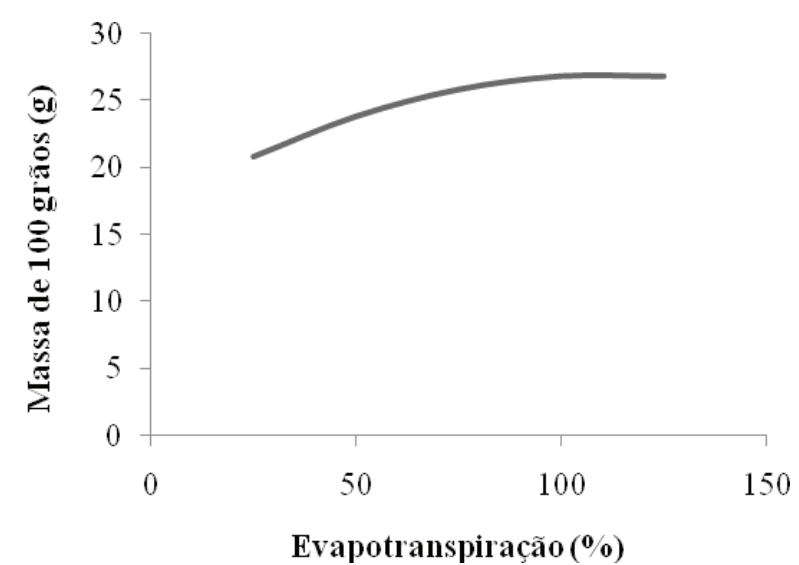

Figura 1. Massa estimada de 100 grãos de feijão em função da reposição da lâmina de evapotranspiração.

$\mathrm{MG}=16,7457+0,18175 E T-0,00081 E T^{2}$

$\mathrm{R}^{2}=0,8484$

em que,

$\mathrm{MG}=$ massa dos grãos (g); e

$\mathrm{ET}=$ reposição da lâmina de evapotranspiração (\%).

Pelos resultados encontrados fica demonstrado que a cultura do feijoeiro é altamente sensível, no que se refere à variável massa dos grãos, à quantidade de água usada na irrigação da cultura. Possivelmente, isso se deva à necessidade da água para formação e transporte de todas as substâncias solúveis, fotossintatos e carbohidratos das fontes (folhas e raízes) aos grãos, onde ocorre a transformação em matéria seca. Calvache (1997), avaliando o efeito da deficiência hídrica e da adubação nitrogenada na produtividade e na eficiência do uso de água na cultura do feijão, encontrou na massa seca de 100 grãos diferenças significativa para o fator quantidade de irrigação. 
O número de vagens por planta foi influenciado pela quantidade de água, conforme se verifica na Figura 2, podendo-se verificar que maiores reposições de lâminas de evapotranspiração proporcionam aumento no número de vagem por plantas, sem ser atingido um ponto de máximo, uma vez que a Equação 2 é quadrática.

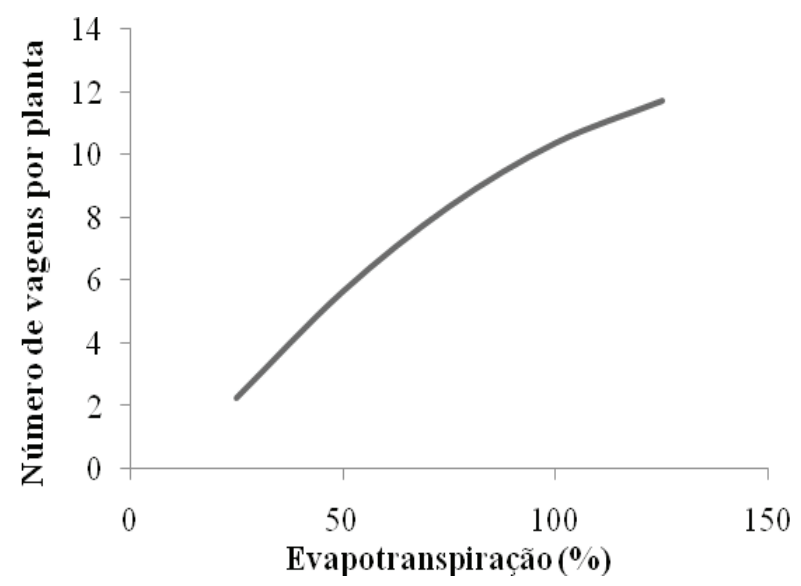

Figura 2. Número de vagens por planta de feijão em função da reposição da lâmina de evapotranspiração.

NVP $=-1,81437+0,17677 \mathrm{ET}-0,000548 \mathrm{ET}^{2}$

$\mathrm{R}^{2}=0,9174$

em que,

$\mathrm{NVP}=$ número de vargens por planta; $\mathrm{e}$

$\mathrm{ET}=$ reposição da lâmina de evapotranspiração (\%).

A quantidade de água fornecida à cultura influenciou diretamente o número de vagens por planta, em virtude de esta variável ser diretamente dependente da umidade no solo. Stone e Moreira (2000) observaram que melhores médias do número de vagens por planta são obtidas quando se cultiva o feijoeiro em melhores condições hídricas do solo.

$\mathrm{O}$ rendimento do número de grãos por vagem foi significativo para as variáveis de profundidade de adubação e para reposição da lâmina de evapotranspiração, determinado pela Equação 3. Na Figura 3 observa-se o comportamento dos dados estimados de número de grãos por vagem em função da reposição da lâmina de evapotranspiração e da profundidade de adubação.

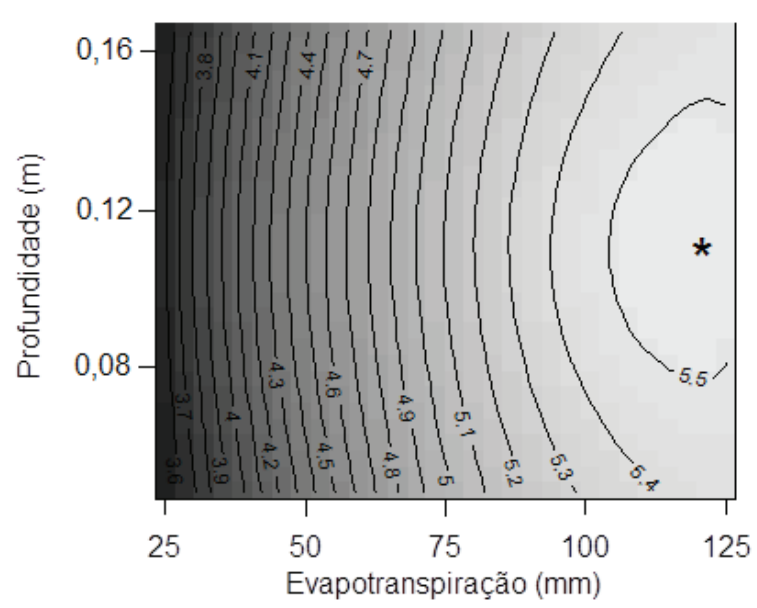

Figura 3. Número estimado de grãos por vagem em função da reposição da lâmina de evapotranspiração (*ponto de máximo).

$\mathrm{NGV}=2,023+8,0012 \operatorname{Pf} 36,0801 P f^{2}+0,05105 \mathrm{ET} \quad 0,0002115 \mathrm{ET}^{2}$

$\mathrm{R}^{2}=0,7367$

em que,

$\mathrm{NGV}=$ número de grãos por vagem;

$\mathrm{Pf}=$ profundidade de adubação $(\mathrm{m})$; e

$\mathrm{ET}=$ reposição da lâmina de evapotranspiração (\%).

O número de grãos por vagens aumentou até o ponto de máximo de 5,548 grãos quando se considera uma lâmina de $120,73 \%$ da evapotranpiração, correspondente a 418,35 mm de água na profundidade de $0,1109 \mathrm{~m}$ de adubação.

Os melhores resultados obtidos neste trabalho se deram, possivelmente, em razão da melhor absorção de nutrientes pelas raízes do feijoeiro na profundidade de $0,11 \mathrm{~m}$, desta forma, externou maior número de grãos por vagens.

Conforme Silveira e Stone (2001), a ocorrência de déficit hídrico do feijoeiro provoca as maiores reduções de produtividade, sendo tanto maior essa redução quanto maior for o período em que a planta for submetida à seca.

A produtividade do feijoeiro foi significativa em função da profundidade de adubação e da lâmina de reposição da evapotranspiração, sendo estimada utilizando-se a Equação 4, cuja curva pode ser visualizada na Figura 4.

\section{REVENG}




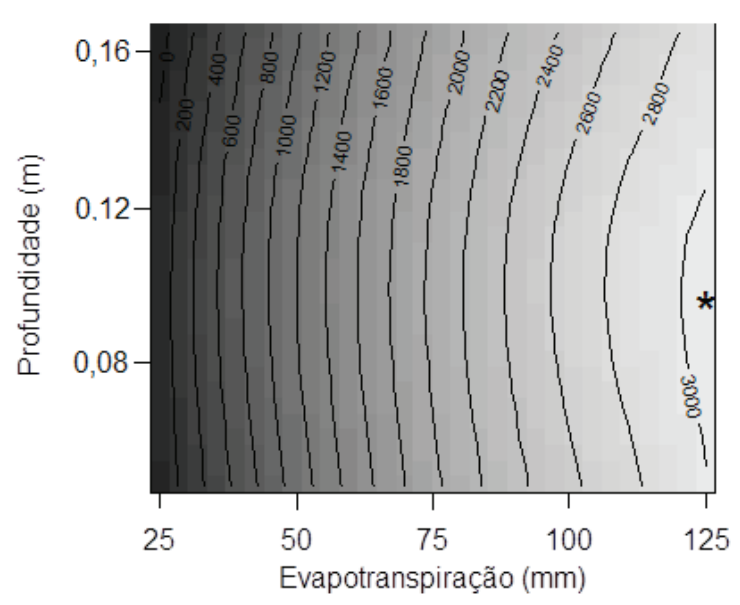

Figura 4. Produtividades estimadas do feijoeiro em função da profundidade de adubação e da lamina de reposição da ETo (*ponto de máximo).

Prod $=-1620,30+9082,57 \mathrm{PF}-47135,7 \mathrm{Pf}^{2}+56,6884 E T-0,18213 E T^{2}$

$\mathrm{R}^{2}=0,7733$

em que,

Prod $=$ produtividade $\left(\mathrm{kg} \mathrm{ha}^{-1}\right)$;

$\mathrm{Pf}=$ profundidade de adubação $(\mathrm{m})$; e

$\mathrm{ET}=$ reposição da lâmina de evapotranspiração (\%).

A produtividade máxima foi de $3.045 \mathrm{~kg} \mathrm{ha}^{-1}$, na profundidade ótima de $0,10 \mathrm{~m}$ de adubação e reposição da lâmina de evapotranspiração de $125 \%$. Observa-se, com base nos resultados obtidos, que o feijoeiro encontrou as melhores condições na profundidade de adubação de 0,09 $\mathrm{m}$, possivelmente em função de melhor aporte de fertilizantes e quantidades de água ideal, refletindo em maior produtividade da cultura.

Herzog et al. (2004), ao analisarem a produtividade de grãos de soja em função da variação da profundidade do adubo, utilizando o sulcador tipo facão, encontraram as produtividades médias de 2.944 e $3.047 \mathrm{~kg} \mathrm{ha}^{-1}$, nas profundidades de 0,06 e $0,12 \mathrm{~m}$, respectivamente.Bizari et al. (2009), trabalhando na região de Campinas-SP, determinou que o consumo de água da cultivar de feijão Carioca Precoce, plantada ao final de junho, foi de $261,3 \mathrm{~mm}$ para uma produtividade de 1.492 $\mathrm{kg} \mathrm{ha} \mathrm{h}^{-1}$.Andrade Júnior et al. (2002) obtiveram produtividades de $2.809 \mathrm{~kg} \mathrm{ha}^{-1}$ e $2.103 \mathrm{~kg} \mathrm{ha}^{-1}$ para as cultivares de feijão-caupi, BR-17 Gurguéia e BR-14 Mulato, respectivamente, em experimento realizado no Litoral Piauiense. As referidas produtividades foram obtidas com o emprego de $449,1 \mathrm{~mm}$ e $389,9 \mathrm{~mm}$ de água, respectivamente.

\section{CONCLUSÕES}

- A profundidade de adubação de $0,09 \mathrm{~m}$ e a reposição da lâmina de evapotranspiração de $125 \%(433,26 \mathrm{~mm}$ de água $)$ proporcionou maior produtividade do feijão;

- A profundidade de adubação de $0,11 \mathrm{~m}$ e lâmina de evapotranspiração de 418,45 mm de água proporcionou maior número de grãos por vagens;

- As lâminas de evapotranspiração influenciam de modo à aumentar a produção das variáveis, massa de 100 grãos e número de vagens por planta;

- As profundidades de adubação estudadas não interferiram nas variáveis, massa de 100 grãos e número de vagens por planta.

\section{AGRADECIMENTOS}

Os autores agradecem ao CNPq e a FAPEMIG pelo auxilio financeiro na realização deste trabalho.

\section{REFERÊNCIAS}

ANDRADE JÚNIOR, A.S.; RODRIGUES, B.H.N.; FRIZZONE, J.A.; CARDOSO, M.J.; BASTOS, E.A.; MELO, F.B. Níveis de irrigação no cultivo do feijão caupi. Revista Brasileira de Engenharia Agrícola e Ambiental, Campina Grande, v.6, n.1, p.17-20, 2002.

BIZARI, D.R.; MATSURA, E.E.; ROQUE, M.M.; SOUZA, A.L. Consumo de água e produção de grãos do feijoeiro irrigado em sistemas plantio direto e convencional. Ciência Rural, v.39, n.7, p.2073-2079, 2009.

BRANQUINHO, K.B.; FURLANI, C.E.A.; LOPES, A; SILVA, R.P.; GROTTA, D.C.C.; BORSATTO,E.A. Desempenho de uma semeadora- 
adubadora direta, em função da velocidade de deslocamento e do tipo de manejo da biomassa da cultura de cobertura do solo. Engenharia Agrícola, Jaboticabal, v.24, n.2, p.374-380, 2004.

CHAIB, S.L.; BULISANI, E.A.; CASTRO, L.H.S.M. Crescimento e produção do feijoeiro em resposta à profundidade da aplicação de adubo fosfatado. Pesquisa Agropecuária Brasileira, Brasília, DF, v.19, n.7, p. 817-822, 1984.

CALVACHE; A.M.; REICHARDT, K.; MALAVOLTA, E.; BACCHI, O.O.S. Efeito da deficiência hídrica e da adubação nitrogenada na produtividade e na eficiência do uso de água em uma cultura do feijão. Scientia Agricola, v.54, n.3, 1997.

HERZOG, R.L.S.; LEVIEN, R.; TREIN, C.R. Produtividade de soja em semeadura direta influenciada por profundidade do sulcador de adubo e doses de resíduo em sistema irrigado e não irrigado. Engenharia Agrícola, Jaboticabal, v.24, n.3, p.771-780, 2004.

KLUTHCOUSKI, J.; STONE, L.F. Potássio: Principais fatores que interferem no crescimento radicular das culturas anuais, com ênfase no potássio. Informações Agronômicas, Piracicaba, n.103, p.5-11, 2003.

LOPES,A.S.; PAVANI, L.C.; CORÁ, J.E.;ZANINI, J.R.; MIRANDA, H.A. Manejo da irrigação (tensiometria e balanço hídrico climatológico) para a cultura do feijoeiro em sistemas de cultivo direto e convencional. Engenharia Agrícola, v.24, n.1, p.89-100, 2004.

ROSOLEM, C.A.; MARUBAYASHI, O.M. Seja o doutor do seu feijoeiro. Informações agronômicas, v.68, p.1-16, 1994. (Encarte especial).

SILVEIRA, P.M.; SILVA, O.F.; STONE, L.F.; SILVA, J.G. Efeitos do preparo do solo, plantio direto e de rotações de culturas sobre o rendimento e a economicidade do feijoeiro irrigado. Pesquisa Agropecuária Brasileira, Brasília, v.36, n.2, p.257-263, 2001.

STONE, L.F.; MOREIRA, J.A.A. Resposta do feijoeiro ao nitrogênio em cobertura, sob diferentes lâminas de irrigação e preparos do solo. Pesquisa Agropecuária Brasileira, Brasília, v.36, n.3, p.473-481, 2000. 